\title{
PERFORMANCE EVALUATION OF CRYOGENIC TREATED TOOLS IN TURNING
}

\author{
Gopal Krishna, P. V.*; Kishore, K. ${ }^{* *}$; Ramadevudu, G. ${ }^{* * *} \&$ Sikandar, Ali*** \\ ${ }^{*}$ Corresponding author, Associate Professor, Department of Mechanical Engineering, Vasavi \\ College of Engineering, Hyderabad, India \\ ${ }^{* *}$ Professor, Department of Mechanical Engineering, Vasavi College of Engineering, \\ Hyderabad, India \\ ${ }^{* \star *}$ Assistant Professor, Department of Physics, Vasavi College of Engineering, Hyderabad, \\ India \\ ${ }^{* * * *}$ P.G. Student, Department of Mechanical Engineering, Vasavi College of Engineering, \\ Hyderabad, India \\ E-mail: gopal_pola@yahoo.co.uk
}

\begin{abstract}
:
Tool wear is a worn portion over the flank and face of the tool. Tool wear is significant for determining tool life and hence it influences the machining economics. The wear measurements are carried by using a tool makers microscope in the present investigations. All the investigations are carried out using cutting fluid. Life enhancement by using cryogenic treatment on HSS is the objective of study. Investigations are carried on different work materials such as AISI 1040, EN8 and EN24. Improvement in tool life up to $90 \%$ is observed for soft material AISI 1040 and enhancement up to 39\% is observed on EN24. These investigations are aimed at benefiting small industries that use aforementioned tool work combinations. Regression models are constructed for tool wear for both untreated machining and cryogenic treated machining.
\end{abstract}

Key Words: Turning, Cryogenic Treatment, Regression Analysis, Tool Wear, Tool Life

\section{INTRODUCTION}

To understand the effects of cryogenic processing, it is essential to get acquainted with the heat treating of metals. The primary reason for heat treating steel is to improve its wear resistance through hardening. Gears, bearings and tooling for example are hardened because they need excellent wear resistance, improved fatigue life, stress relieving dimensional stability and corrosion resistance for extended reliability and performance. The steps in heat-treating are frequently explained in a simplistic manner but it takes significant skill and experience to execute heat treatments successfully. The steel tooling in practice would be immersed in liquid nitrogen for a period of time, allowed to warm up and then placed into service. It was also observed that the cryogenic treatment would convert the retained austenite into un-tempered martensite. The tools would experience a greatly enhanced service life. It was theorized that the increase in wear resistance was a direct result of the reduction in the amount of residual austenite. Liquid nitrogen systems have been the customary method for achieving cryogenic temperatures. Three types of systems have been developed viz heat exchanger systems, direct spray systems, and immersion systems. The last method i.e immersion system is used in present investigation.

The tool wear can be measured directly by using a microscope. However several indirect methods depending on the measurement of a parameter that influence the tool wear do exist. Some of the methods for indirect prediction are cutting force, vibrations, acoustics, radioactive isotopes, image processing etc. It should be noted that no method is accurate for indirect prediction. Studies by Penn State University researchers in 1996 showed that retained austenite was reduced from near $18 \%$ to roughly $8 \%$ in $\mathrm{T} 15$ tool steel upon cryogenic treatment. Hardness increased by 2 points (HRC) with cryogenic treatment and 
subsequently decreased (in some cases more than 2 points) after a temper cycle. Still there has not yet been enough investigation to precisely determine optimum processing parameters, even for tool steels. Some researchers suggest that tools should be sharpened after cryogenic treatment rather than before. However for present work cryogenic treatment was carried out after grinding the single point cutting tool to the required angles. The tools are dipped in liquid nitrogen $\left(-196^{\circ} \mathrm{C}\right)$ up to 24 hours and they are slowly brought to room temperature.

The application of cryo-treated tools in metal cutting is a fascinating one and many investigators have shown keen interest in this area. Tool wear studies were carried out by Gill [1] et al on tungsten carbide cutting tools while turning AISI 1040. Wear studies on milling cutter treated by liquid nitrogen were performed by Young [2] et al. The influence of cryogenic treatment on the mechanical properties of tool steels were carried out by Molinari [3] et al. Structural changes in T-I type high speed steels when subjected to cryogenic treatment are reported by Popandopulo [4] et al. The lucid explanation by Carlson [5] about cold treatment of steels in his contribution for ASM hand book was a major inspiration for this work. Most of the modern investigators in the field of metal cutting preferred to use liquid nitrogen as a substitute coolant and they could obtain some improvements in cutting conditions. Yakup [6] et al was one of the investigators who tried to establish improvement of tool life due to a flood of liquid nitrogen. An overview on the performance of tool material after cryogenic treatment was presented as a review paper by Rupinder Singh [7] et al. Machining properties of titanium based alloy by cryogenic treated carbides and HSS tools was carried out by Aujla [8]. Improvement in cutting conditions using various means is a significant issue in the area of manufacturing as it effects cost. Hence present studies attain significance in the context of extending the cryogenic treatment methods to small industries.

\section{EXPERIMENTATION}

Although a lot of choices are available for the industry, so far as tool materials are concerned, it is to be noted that most of the presently used multipoint cutting tools are made of HSS. This tool material has high toughness and is capable of taking impact loads. On the other hand still single point cutting tools made of HSS are routinely used in small and medium machine shops, which cannot effort experience tools made of carbides or ceramics. An attempt is made in the present work to improve the tool life of single point cutting tools made of HSS, by exposing them to liquid nitrogen $(-1960 \mathrm{C})$. This cryogenic liquid is commercially available at very low cost.

The machining parameters considered during the current investigations to evaluate the tool life are the cutting speed, feed and depth of cut. Experiments are conducted using an $L_{8}$ orthogonal array designed by Taguchi and the response is measured. All the experiments are conducted on work pieces of length $600 \mathrm{~mm}$ and six passes are taken over them before measuring the tool wear. The wear is measured by using a Tool makers' microscope. All the experiments are conducted at random to avoid error and bias, each condition is repeated for confirmation of wear. The work materials selected in the present investigations are AISI 1040, EN8 and EN24. The reason for selecting these materials is that most of the small and medium scale industries fabricate components made of these materials only. The present studies are targeted to benefit only these industries which cannot afford expensive tool materials, machines and necessary equipment for measurement of tool wear. The depth of cut is maintained constant at $1 \mathrm{~mm}$ and the feed rate at $0.3 \mathrm{~mm} / \mathrm{rev}$. A total of six passes are taken for a machining time of 24 minutes.

The tool material used in the present investigations is T-1type HSS with $5 \%$ cobalt. The tools are ground to ASA standard $11^{\circ}-12^{0}-7^{0}-7^{0}-15^{\circ}-20^{\circ}-0.5 \mathrm{~mm}$, on a tool and cutter grinder. A set of these tools are subjected to liquid nitrogen treatment for a period of $24 \mathrm{hrs}$ and are slowly brought to room temperature. 


\section{RESULTS AND DISCUSSIONS}

Tool wear and tool life are in separable in metal cutting industry. The machining parameters are set based on the final constraints such as quality of surface finish and productivity. The tool life will come to an end due to progressive wear or due to premature failure of the tool. The former is the main reason for most of the tools used in industry. An attempt is made in the present work to improve the tool life by performing cold (cryogenic) treatment. This treatment brings about structural changes in cutting tools made of steel. Figures 1 and 2 respectively show microscope images of the tool before and after cryogenic treatment.

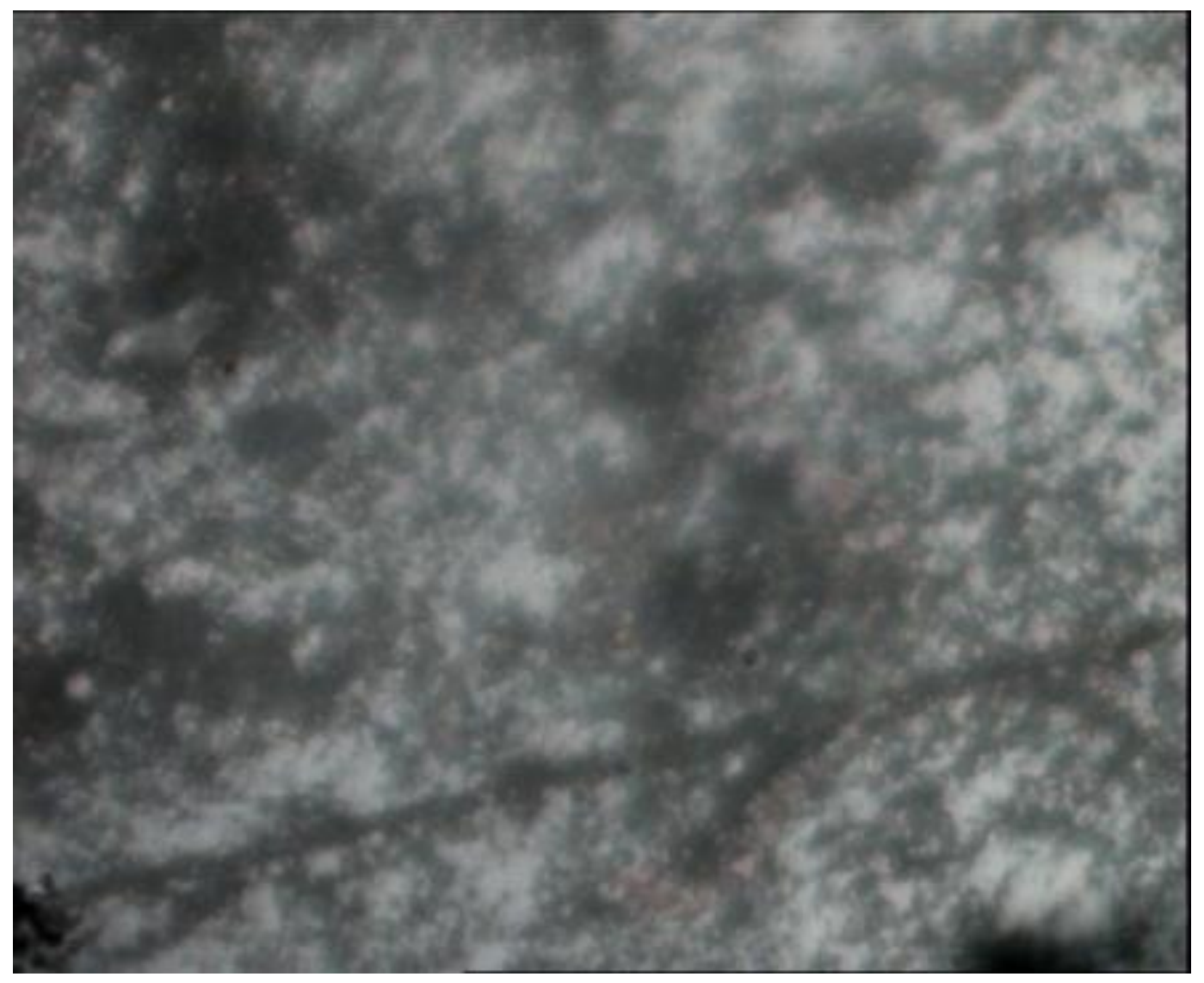

Figure 1: Image of cutting tool before cryogenic treatment (magnification X600). 


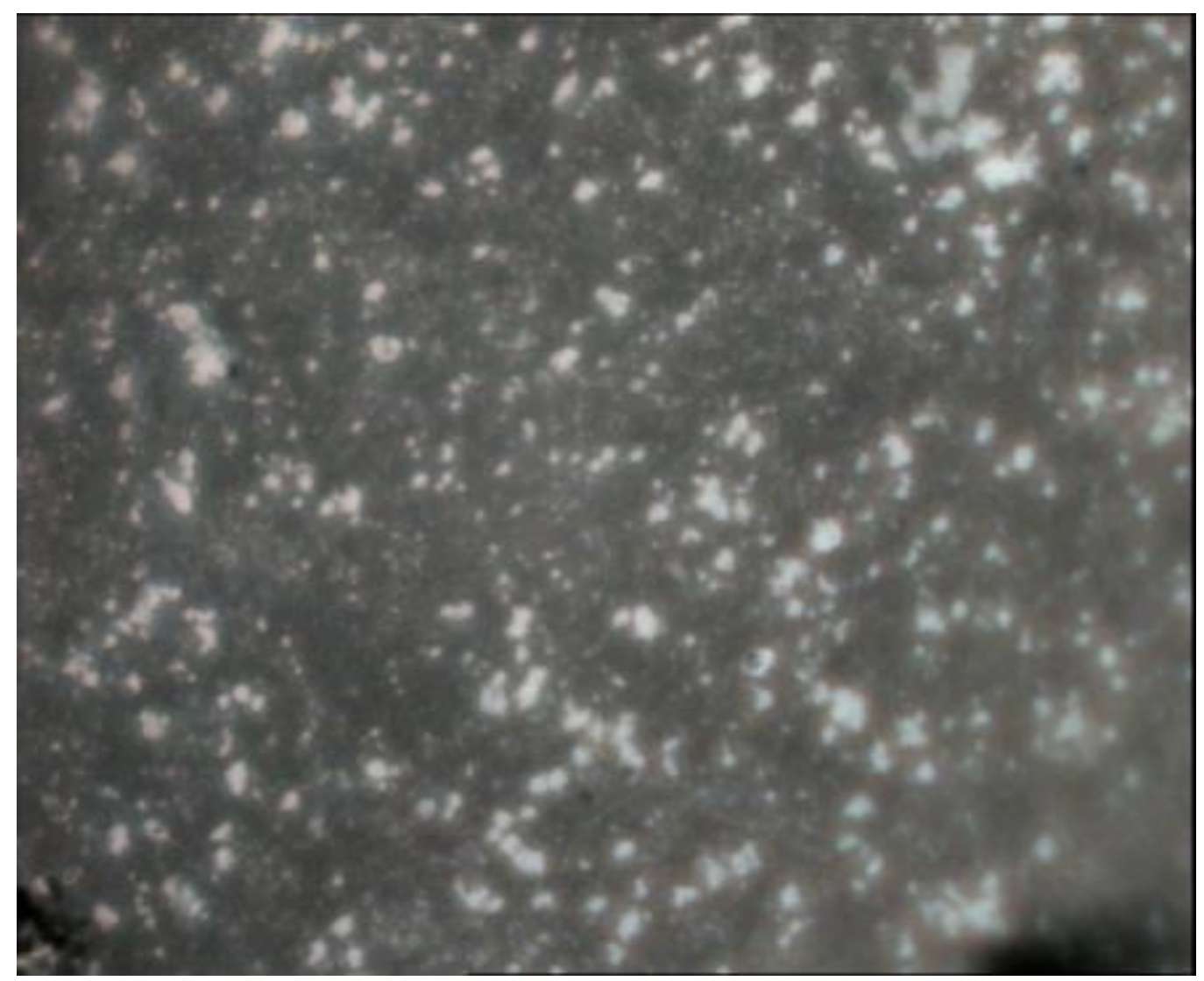

Figure 2: Image of cutting tool after 24 hours cryogenic treatment (magnification X600).

The levels selected for the machining parameters and experimental matrix used for different work materials are shown in Tables I to IV. All experiments are carried out for wet condition only. The cutting fluid used is a water oil emulsion.

Table I: Selection of process parameters.

\begin{tabular}{|c|c|c|c|}
\hline Level & $\begin{array}{c}\text { Cutting speed V (m/min) } \\
\mathbf{x}_{\mathbf{1}}\end{array}$ & $\begin{array}{c}\text { Feed S (mm/rev) } \\
\mathbf{x}_{\mathbf{2}}\end{array}$ & $\begin{array}{c}\text { Depth of cut } \mathbf{t}(\mathbf{m m}) \\
\mathbf{x}_{\mathbf{3}}\end{array}$ \\
\hline Level-1 & 40 & 0.798 & 1.0 \\
\hline Level-2 & 26 & 0.227 & 0.5 \\
\hline
\end{tabular}


Table II: Tool Wear for machining of AISI 1040.

\begin{tabular}{|c|c|c|c|c|c|c|}
\hline $\begin{array}{c}\text { S. } \\
\text { No }\end{array}$ & $\begin{array}{c}\text { Cutting } \\
\mathbf{s p e e d}(\mathbf{V}) \\
(\mathbf{m} / \mathbf{m i n}) \\
\mathbf{x}_{\mathbf{1}}\end{array}$ & $\begin{array}{c}\text { Feed } \\
\mathbf{( \mathbf { S } )} \\
(\mathbf{m m} / \mathbf{r e} \\
\mathbf{v}) \mathbf{x}_{\mathbf{2}}\end{array}$ & $\begin{array}{c}\text { Depth } \\
\text { of cut } \\
\mathbf{( t )} \\
(\mathbf{m m}) \mathbf{x}_{\mathbf{3}}\end{array}$ & $\begin{array}{c}\text { Tool wear } \\
\text { Without } \\
\text { cryogenic } \\
\text { treatment } \\
(\mathbf{m m})\end{array}$ & $\begin{array}{c}\text { Tool wear with 24 } \\
\text { hour cryogenic } \\
\text { treatment } \\
\mathbf{( m m})\end{array}$ & $\begin{array}{c}\% \\
\text { Increase } \\
\text { in Tool } \\
\text { life. }\end{array}$ \\
\hline 1. & 1 & 1 & 1 & 0.6 & 0.306 & 49.00 \\
\hline 2. & 1 & 1 & 2 & 0.49 & 0.248 & 49.38 \\
\hline 3. & 1 & 2 & 1 & 0.37 & 0.168 & 54.59 \\
\hline 4. & 1 & 2 & 2 & 0.315 & 0.185 & 41.26 \\
\hline 5. & 2 & 1 & 1 & 0.29 & 0.136 & 53.10 \\
\hline 6. & 2 & 1 & 2 & 0.28 & 0.127 & 54.64 \\
\hline 7. & 2 & 2 & 1 & 0.185 & 0.055 & 70.27 \\
\hline 8. & 2 & 2 & 2 & 0.12 & 0.012 & 90.00 \\
\hline
\end{tabular}

Table III: Tool Wear for machining of EN8.

\begin{tabular}{|c|c|c|c|c|c|c|}
\hline $\begin{array}{c}\text { S. } \\
\text { No }\end{array}$ & $\begin{array}{c}\text { Cutting } \\
\mathbf{s p e e d}(\mathbf{V}) \\
(\mathbf{m} / \mathbf{m i n}) \\
\mathbf{x}_{\mathbf{1}}\end{array}$ & $\begin{array}{c}\text { Feed } \\
\mathbf{( S )} \\
(\mathbf{m m} / \mathbf{r e} \\
\mathbf{v}) \mathbf{x}_{\mathbf{2}}\end{array}$ & $\begin{array}{c}\text { Depth } \\
\text { of cut } \\
\mathbf{( t )} \\
(\mathbf{m m}) \\
\mathbf{x}_{\mathbf{3}}\end{array}$ & $\begin{array}{c}\text { Tool wear } \\
\text { Without } \\
\text { cryogenic } \\
\text { treatment } \\
(\mathbf{m m})\end{array}$ & $\begin{array}{c}\text { Tool wear with 24 } \\
\text { hour cryogenic } \\
\text { treatment } \\
\mathbf{( m m )}\end{array}$ & $\begin{array}{c}\% \\
\text { Increase } \\
\text { in } \\
\text { Tool life. }\end{array}$ \\
\hline 1. & 1 & 1 & 1 & 1.05 & 0.675 & 35.71 \\
\hline 2. & 1 & 1 & 2 & 0.88 & 0.655 & 25.56 \\
\hline 3. & 1 & 2 & 1 & 0.61 & 0.41 & 32.78 \\
\hline 4. & 1 & 2 & 2 & 0.56 & 0.385 & 31.25 \\
\hline 5. & 2 & 1 & 1 & 0.48 & 0.345 & 28.12 \\
\hline 6. & 2 & 1 & 2 & 0.45 & 0.315 & 30.00 \\
\hline 7. & 2 & 2 & 1 & 0.315 & 0.145 & 53.96 \\
\hline 8. & 2 & 2 & 2 & 0.24 & 0.105 & 56.25 \\
\hline
\end{tabular}

Table IV: Tool Wear for machining of EN24.

\begin{tabular}{|c|c|c|c|c|c|c|}
\hline $\begin{array}{c}\text { S. } \\
\text { No }\end{array}$ & $\begin{array}{c}\text { Cutting } \\
\mathbf{s p e e d}(\mathbf{V}) \\
(\mathbf{m} / \mathbf{m i n}) \\
\mathbf{x}_{\mathbf{1}}\end{array}$ & $\begin{array}{c}\text { Feed } \\
\mathbf{( S )} \\
(\mathbf{m m} / \mathbf{r e} \\
\mathbf{v}) \mathbf{x}_{\mathbf{2}}\end{array}$ & $\begin{array}{c}\text { Depth } \\
\text { of } \mathbf{c u t} \\
\mathbf{( t )} \\
(\mathbf{m m})\end{array}$ & $\begin{array}{c}\text { Tool wear } \\
\text { Without } \\
\text { cryogenic } \\
\text { treatment } \\
(\mathbf{m m})\end{array}$ & $\begin{array}{c}\text { Tool wear with 24 } \\
\text { hour cryogenic } \\
\text { treatment } \\
\mathbf{( m m})\end{array}$ & $\begin{array}{c}\% \\
\text { Increase } \\
\text { in } \\
\text { Tool life. }\end{array}$ \\
\hline 1. & 1 & 1 & 1 & 1.060 & 0.650 & 38.69 \\
\hline 2. & 1 & 1 & 2 & 1.380 & 0.930 & 32.60 \\
\hline 3. & 1 & 2 & 1 & 1.100 & 0.830 & 24.45 \\
\hline 4. & 1 & 2 & 2 & 0.875 & 0.770 & 12.00 \\
\hline 5. & 2 & 1 & 1 & 0.685 & 0.505 & 26.27 \\
\hline 6. & 2 & 1 & 2 & 0.635 & 0.440 & 30.70 \\
\hline 7. & 2 & 2 & 1 & 0.510 & 0.350 & 31.37 \\
\hline 8. & 2 & 2 & 2 & 0.450 & 0.320 & 28.88 \\
\hline
\end{tabular}


The influence of tool wear on various machining parameters is analyzed on AISI 1040, EN8 and EN24 working materials. A few more experiments are conducted to obtain the relation between cutting speed and flank wear for all the work materials.

The flank wear in the tool materials selected for the present study with the speed for untreated and cryo-treated samples are shown in Figure 3. It was observed that for the materials like AISI 1040, EN8, EN24 cutting speed has significant influence on tool life when compared to feed and depth of cut for both untreated and cryogenic treated HSS single point cutting tool. It was also found that the interaction of speed, feed and depth of cut is more for untreated tool than cryogenic treated tool. The interaction of speed and feed is more on EN8 when compared to AISI 1040 and EN24 on both untreated and cryogenic treated tool.
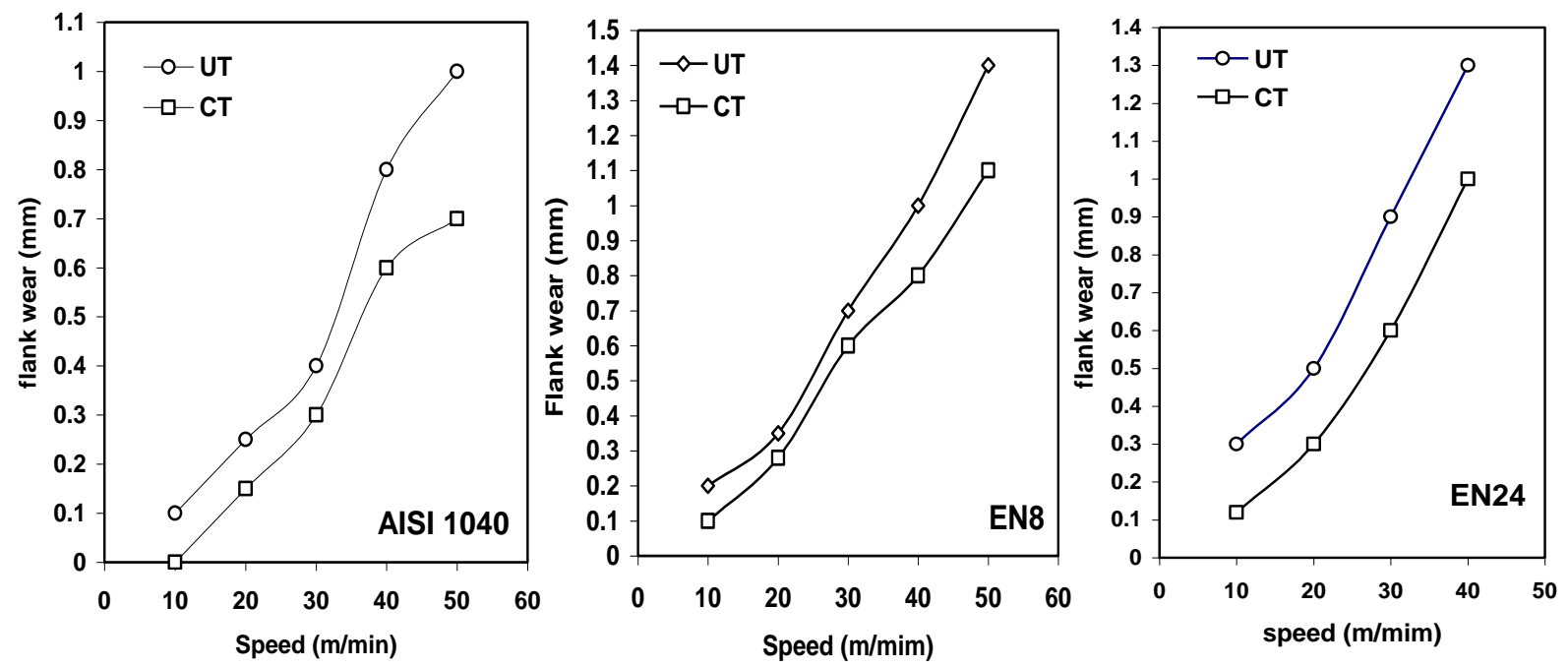

Figure 3: Variation of flank wear with speed in untreated and cryo-treated tools AISI 1040, EN8 and EN24 for a machining period of 24 minute.

It is evident from Figure 3 that the flank wear is less in all the cryo-treated sample tools i.e. AISI 1040, EN8 and EN24 compared to untreated tools at various speeds. So the low wear in the cryo-treated tools can be attributed to micro-hardening of the tools due to immersion in liquid nitrogen. The grain size on surface of the tool might have changed due to the cryogenic treated and hardened the tool.

A negative influence has been observed in the interaction of speed and depth of cut on both the tools. However, the interaction of feed and depth of cut has little influence on both treated and untreated material.

The regression analysis has been conducted on the data and the results are presented in Table $\mathrm{V}$. The parameters in the regression analysis are speed $\left(\mathrm{x}_{1}\right)$, feed $\left(\mathrm{x}_{2}\right)$ and depth of cut $\left(\mathrm{x}_{3}\right)$. From the regression analysis it can be concluded that the life of the tool increases by cryogenic treatment for both soft and hard materials. Hence cryogenic treated tools are found to be most effective at high speeds and feeds. 
Table V: Regression equations for various working materials.

\begin{tabular}{|c|c|c|}
\hline $\begin{array}{l}\text { Working } \\
\text { Material }\end{array}$ & Tool wear $(\mathrm{mm})$ for Untreated HSS & $\begin{array}{c}\text { Tool wear }(\mathrm{mm}) \text { for Cryogenic } \\
\text { treated HSS for } 24 \text { hours }\end{array}$ \\
\hline $\begin{array}{c}\text { AISI } \\
1040\end{array}$ & $\begin{aligned} y= & 0.33125+0.1125 x_{1}+0.08375 x_{2}+ \\
& 0.03 x_{3}+0.28 x_{1} x_{2}-0.2 x_{3} x_{1}+ \\
& 0.22 x_{1} x_{2} x_{3}\end{aligned}$ & $\begin{aligned} y= & 0.143688+0.060813 x_{1} \\
& +0.038188 x_{2}+0.000313 x_{3}- \\
& 0.171 x_{1} x_{2}-0.099 x_{2} x_{3}-0.489 x_{3} x_{1} \\
& +0.0399 x_{1} x_{2} x_{3}\end{aligned}$ \\
\hline EN8 & $\begin{aligned} y= & 0.575625+0.201875 x_{1}+ \\
& 0.140625 x_{2}+0.039375 x_{3}+0.75 \\
& x_{1} x_{2}+0.15 x_{2} x_{3}-0.31 x_{3} x_{1}+0.33 \\
& x_{1} x_{2} x_{3}\end{aligned}$ & $\begin{aligned} y= & 0.379375+0.151875 x_{1}+ \\
& 0.118125 x_{2}+0.014375 x_{3}+0.25 \\
& x_{1} x_{2}-0.03 x_{2} x_{3}-0.73 x_{3} x_{1}+0.01 \\
& x_{1} x_{2} x_{3} .\end{aligned}$ \\
\hline EN24 & $\begin{aligned} y= & 0.899375+0.329375 x_{1}+ \\
& 0.165625 x_{2}+0.064375 x_{3}+1.21 \\
& x_{1} x_{2}-0.11 x_{2} x_{3}+0.09 x_{3} x_{1}- \\
& 0.07 x_{1} x_{2} x_{3}\end{aligned}$ & $\begin{aligned} y= & 0.651875+0.244375 x_{1}+ \\
& 0.084375 x_{2}-0.01438 x_{3}+0.15 \\
& x_{1} x_{2}+1.05 x_{2} x_{3}-0.25 x_{3} x_{1}- \\
& 0.79 x_{1} x_{2} x_{3}\end{aligned}$ \\
\hline
\end{tabular}

\section{CONCLUSIONS}

The cold treatment on HSS single point cutting tools in the present study has shown significant influence on the tool life. The tool life improvement up to $90 \%, 50 \%$ and $39 \%$ respectively are observed while machining AISI 1040, EN8 and EN24 during the experiments. The interaction of speed, feed and depth of cut is more for untreated tool than cryogenic treated tool, this is evident from the regression analysis. The interaction of speed and feed is more on EN8 when compared to AISI 1040 and EN24 on both untreated and cryogenic treated tool. It can be concluded that the life of the tools has increased due to cryogenic treatment while machining both soft and hard materials. The cryogenic treated tools are found to be most productive at high speeds and feeds. These findings will benefit small and medium machining shops.

\section{ACKNOWLEDGEMENT}

The authors are sincerely thankful to the Principal and Management of Vasavi College of Engineering for extending their support in carrying out this work. The cooperation extended by Mr. T. Manohar Reddy, Lab Technician, during experimentations is highly appreciated.

\section{REFERENCES}

[1] Gill, S.S., Singh, R. and Singh,J., 2008, "Wear behavior of cryogenically treated tungsten carbide inserts under dry and wet turning conditions", International Journal of Machine Tools Manufacturing, 49(3-4), 256-260

[2] Young, A.Y.L., Seah, K.H.W. and Rahman, M. 2006, "Performance evaluation of Cryogenically treated tungsten carbide tools in turning Operation", International journal of machine tools manufacturing technology, 46, 2051-2056

[3] Molinari, A., Pellizzari.M., Gialanella, S., Straffelini, G. and Stiasny, K.H., 2001 " effect of deep cryogenic treatment on the mechanical properties of tool steels", Journal of Material Processing Technology 118(1-3) 35-355

[4] Popandopulo, N. and Zhukova, L.T., 1980, "Transformation in high speed steels during Cold treatment", Met Sci Heat Treat, 22(10), 708-71

[5] Caarlson,E.A., 1990, "Cold treating and cryogenic treatment of steel in ASM Hand book," Vol.4 Heat Treating, ASM international, 1oth Ed., Metals Park, OH

[6] Yakup Yildiz, Muammer Nalbant, 2008 "A review of cryogenic cooling in machining processes", International Journal of Machine Tools and Manufacture, 48 (9) 947-964

[7] Rupinder Singh and Kamalijit Singh, 2010, "Enhancement of Toll Material Machining Characteristics with Cryogenic Treatment: A Review", proceedings of the 2010 International 
Conference on Industrial Engineering and operations management, Dhaka, Bangladesh, January 9-10,2010

[8] Aujla,H.S. and Singh,R., 2008, "Applications of cryogenic treatment for Enhancing the Machining Properties of Titanium Alloy (Ti-6Al-4V)," Manufacturing Technology Today, 7(10), 22-26

[9] Vishal S. Sharma, Manu Dogra, N.M. Suri , 2009, "Cooling techniques for improved productivity in turning", International Journal of Machine Tools and Manufacture, Volume 49, Issue 6, Pages 435-453

[10] M. Dhananchezian, M. Pradeep Kumar, 2010 "Experimental investigation of cryogenic cooling by liquid nitrogen in the orthogonal machining of aluminium 6061-T6 alloy" International Journal of Machining and machinability of Materials - Vol. 7, No.3/4 pp. 274 - 285

[11] S.Chatterjee,1992,"Performance characteristics of cryogenically treated high speed drills", International journal of production research volume 30, no 4, 773-786

[12] David N. Collins, 1999 "Cryogenic treatment of tool steels", Advanced materials and Process, December

[13] R.F. Barron, 1982 "Cryogenic treatment to improve wear resistance", Butterworth \& Co Ttd,

[14] Reitz.W, Pendray.J, 2001 "Cryoprocessing of materials- A review of current status", Materials and manufacturing process 